Article

\title{
What Value Does the Public Put on Managing and Protecting an Endangered Marine Species? The Case of the Finless Porpoise in South Korea
}

\author{
Ju-Hee Kim, Joseph Kim and Seung-Hoon Yoo*(D) \\ Department of Energy Policy, Graduate School of Energy \& Environment, Seoul National University of Science \& \\ Technology, 232 Gongreung-Ro, Nowon-Gu, Seoul 01811, Korea; jhkim0508@seoultech.ac.kr (J.-H.K.); \\ josephkim@seoultech.ac.kr (J.K.) \\ * Correspondence: shyoo@seoultech.ac.kr; Tel.: +82-2-970-6802
}

Received: 28 March 2020; Accepted: 27 May 2020; Published: 2 June 2020

check for updates

\begin{abstract}
In South Korea, the finless porpoise (FP) is one of representative endangered marine species. The country is trying to manage and protect FPs through several costly measures and demands information about what value the public puts on the management and protection. This article, therefore, explores the South Korean public perspective on managing and protecting FP using a contingent valuation (CV) technique. More specifically, the data on the public willingness to pay (WTP) for the management and protection were collected from a CV survey of 1000 households across the country, adopting a dichotomous choice question format. The household yearly WTP for the management and protection was estimated, with statistical significance, to be $2730 \mathrm{KRW}$ (2.32 USD). If this value is expanded to all households in South Korea, the national value amounts to 54.19 billion KRW (46.00 million USD) per annum. This can be interpreted as the economic value or benefit of managing and protecting FP.
\end{abstract}

Keywords: finless porpoise; endangered marine species; management and protection; contingent valuation; economic value; willingness to pay

\section{Introduction}

An increasing recognition of the importance of biodiversity leads many international organizations to adopt a policy of managing and protecting endangered species from the threat of extinction. For example, the International Union for Conservation of Nature has established the 'Red List of Threatened Species' since 1964 as an indicator of the health of the world's biodiversity. Currently, there are more than 98,500 species on the Red List, and more than 27,000 species on the Red List are threatened with extinction [1]. Therefore, managing and protecting endangered marine species has become one of the important issues in the establishment and enforcement of marine policy.

The Korea Ministry of Oceans and Fisheries (KMOF), a government organization, has enacted the 'Conservation and Management of Marine Ecosystems Act' [2]. Based on this Act, the KMOF introduced a management system for endangered marine species in 2006 called 'The list of protection for endangered marine species (List of protection)'. This list of protection has targeted marine species rapidly becoming extinct or of great academic and economic value. Currently, 77 marine species, including mammals, seabirds, and shorebirds, contained in this list of protection are being monitored and managed [3].

The finless porpoise (FP), Neophocaena phocaenoides, is one of the porpoise species belonging to the mammals. The FP was registered on this list of protection in 2016. FPs are the only fresh-water-adapted porpoise in the world [4]. The FP matures sexually when it is about six years old, and only one calf is born at a time [5]. The FP has a very low natural rate of increase, that is, slow recovery of the population. 
The number of mature FP individuals is estimated to have been continuously reduced from 36,000 in 2004 to 17,000 in 2017 due mainly to climate change, incidental catch, pollution, and natural system modifications caused by human activities. In particular, the main reason for the death of mature FPs is incidental catch. According to the National Institute of Fisheries Science, in South Korea, an average of about 12,000 FPs per year died from being caught or trapped in fishing gear from 2012 to 2016, of which about $83 \%$ were found to have died trapped in fishing gear.

The FP, which lives mainly around West Sea of South Korea, represents one of the endangered marine species [3]. Therefore, the South Korean government is trying to manage and protect FPs in order to maintain their population. However, it costs a lot of money to do this. For example, the government prohibits the capture or trade of FPs, which requires monitoring to ensure the effectiveness of the prohibition, and thus requires public spending on the monitoring. The government also plans to continue to invest in research and development to develop new fishing nets that can prevent FPs from unintentionally being caught. A fishing net from which small FPs can escape was developed in 2016 [3]. If an FP is found unintentionally injured in the fishing process or off the coast, the government should treat it well and release it into the wild sea, which costs a lot. For instance, the government treated a dolphin that was illegally caught in 2009 and released it in 2013 after undergoing wild adaptation training, with a total cost of 0.75 billion KRW (0.7 million USD) [6]. In addition, the Marine Life Treatment Center, which was established on Jeju Island, South Korea to protect marine species, cost a total of 0.3 billion KRW ( 0.3 million USD) to build the facilities alone.

Such measures are being carried out similarly overseas. According to Davies and Kimberley [7], in Canada, monitoring and risk reduction regulations and activities were implemented in 2017 to protect whales. A Massachusetts aquarium and engineering firm in the U.S. are developing a way to monitor whales using satellites to protect endangered species [8]. The International Maritime Organization, a United Nations organization that deals with all aspects of maritime safety and the protection of the marine environment, has re-designated ship routes to prevent whales from colliding with ships and reducing their populations [9].

The management and protection of the FPs requires considerable expenditure. This expenditure should be covered by taxes, which will be borne by the general public, who are taxpayers. Since public funds raised from taxes should be used in socially beneficial places, information about the economic value of implementing the management and protection is needed to determine whether it is socially beneficial or not. After all, the government is demanding that researchers should estimate the economic value of managing and protecting FPs.

For the purpose of meeting this demand, this study attempts to estimate the economic value or benefits ensuing from managing and protecting FPs by applying the contingent valuation (CV) method based on a nationwide survey of 1000 South Korean households. This corresponds with the practice adopted in some former studies [10-18] that also utilized the CV method to value marine species. In addition, from an academic perspective, this study aims to add a study case for FP because there is so far a lack of research cases for FP. There are three sections in the rest of the article. An explanation of the methodology is given in Section 2. The theoretical background and application procedures of the $\mathrm{CV}$ technique as the main technique used in the article will be described. Section 3 explains the data, addresses the results, and reports the implications of the results. The final section is devoted to presenting conclusions.

\section{Methodology}

\subsection{Literature Review}

The previous studies are summarized in Table 1. There have been studies on the economic value of endangered marine species in other countries, which mainly applied the stated preference method. There are two main approaches, CV and choice experiment (CE). Giraud et al. [10] estimated the yearly household willingness to pay (WTP) for conserving the Steller sea lion in the United States as 
61.13 USD by using the CV method. Stithou and Scarpa [11] and Bosetti and Pearce [12] conducted a $\mathrm{CV}$ to estimate the economic value of the seal in the UK, and the turtle and seal in Greece, respectively. Dong [13] assessed the economic value of Yangtze FP in China as 9.94, 5.92, and 6.67 EUR per household per year in three Chinese cities (Beijing, Guangzhou, and Nanchang), respectively, by using a CV. Lim et al. [14] found that the South Korean household's WTP for restoring Dokdo seals was 4.86 USD per annum by applying a CV. A study of Boxall et al. [15] in Canada put the values of 77 to 229 USD on different levels of marine mammal recovery programs. Bond et al. [16] used the CV method to examine the value of the Steller sea lion. Lew et al. [17] applied the CE method to estimate WTP for increasing Steller sea lion population by region (eastern, western) and scenario version (decreasing, stable, and increasing). In addition, there are many other studies that estimate the WTP for endangered marine species, which are used as basic data for benefit transfer or environmental value transfer [18].

Table 1. Summary of the literature review dealing with the marine endangered species.

\begin{tabular}{|c|c|c|c|c|}
\hline Sources & $\begin{array}{l}\text { Object to be } \\
\text { Valued }\end{array}$ & Countries & Main Results & Method $^{\text {a }}$ \\
\hline $\begin{array}{l}\text { Giraud } \\
\text { et al. [10] }\end{array}$ & $\begin{array}{l}\text { Steller sea } \\
\quad \text { lion }\end{array}$ & $\begin{array}{l}\text { United } \\
\text { States }\end{array}$ & $\begin{array}{l}61.13 \text { USD per household per year for conserving } \\
\text { the Steller sea lion }\end{array}$ & $\mathrm{CV}$ \\
\hline $\begin{array}{l}\text { Stithou } \\
\text { and Scarpa } \\
\text { [11] }\end{array}$ & $\begin{array}{l}\text { Loggerhead } \\
\text { Turtle and } \\
\text { Monk seal }\end{array}$ & Greece & $\begin{array}{l}\text { Under donation, } 22.52 \text { EUR per respondent for } \\
\text { turtles and } 20.94 \text { EUR per respondent for seals. } \\
\text { Under a landing fee, } 12.04 \text { EUR per respondent } \\
\text { for turtle and } 12.40 \text { EUR per respondent for seal }\end{array}$ & $\mathrm{CV}$ \\
\hline $\begin{array}{l}\text { Bosetti and } \\
\text { Pearce [12] }\end{array}$ & Grey seal & England & $\begin{array}{l}\text { An amount of } 8 \text { GBP per person for recreational } \\
\text { use of seals and } 9 \text { GBP per person for seeing seals } \\
\text { in the wild }\end{array}$ & $\mathrm{CV}$ \\
\hline Dong [13] & $\begin{array}{l}\text { Finless } \\
\text { porpoise }\end{array}$ & China & $\begin{array}{l}\text { Economic value of finless porpoise is } 9.94,5.92, \\
\text { and } 6.67 \text { EUR per household per year in three } \\
\text { Chinese cities (Beijing, Guangzhou, } \\
\text { and Nanchang), respectively. }\end{array}$ & $\mathrm{CV}$ \\
\hline $\begin{array}{l}\text { Lim et al. } \\
\text { [14] }\end{array}$ & Dokdo seal & South Korea & $\begin{array}{l}\text { An amount of } 4.86 \text { USD per household for } \\
\text { implementation of the Dokdo seal } \\
\text { restoration project }\end{array}$ & $\mathrm{CV}$ \\
\hline $\begin{array}{l}\text { Boxall et al. } \\
\text { [15] }\end{array}$ & $\begin{array}{l}\text { Marine } \\
\text { mammal }\end{array}$ & Canada & $\begin{array}{l}\text { An amount of } 77 \text { to } 229 \text { USD per year per } \\
\text { household for different levels of marine mammal } \\
\text { recovery programs }\end{array}$ & $\mathrm{CV}$ \\
\hline $\begin{array}{l}\text { Bond et al. } \\
\quad[16]\end{array}$ & $\begin{array}{l}\text { Steller sea } \\
\quad \text { lion }\end{array}$ & $\begin{array}{l}\text { United } \\
\text { States }\end{array}$ & $\begin{array}{l}\text { Mean willingness to pay for } 5 \text { and } 15 \text { year } \\
\text { repayment periods is } 46 \text { USD per year for } \\
\text { protecting Steller sea lions }\end{array}$ & $\mathrm{CV}$ \\
\hline $\begin{array}{l}\text { Lew et al. } \\
\text { [17] }\end{array}$ & $\begin{array}{l}\text { Steller sea } \\
\text { lion }\end{array}$ & $\begin{array}{l}\text { United } \\
\text { States }\end{array}$ & $\begin{array}{l}\text { An amount of } 39.26 \text { to } 229.47 \text { USD per household } \\
\text { per year for increasing Steller sea lion population }\end{array}$ & $\mathrm{CE}$ \\
\hline
\end{tabular}

\subsection{Contingent Valuation}

Obtaining the demand function for a non-market good is quite complicated. Because there are no transaction data for the good in the market, the data that are necessary for obtaining the demand function are not available [19]. According to microeconomic theory, the area below the demand curve implies WTP [20-22]. In fact, when dealing with a non-market good, we often need information about the area below the demand curve, that is, the economic benefits ensuing from consuming a non-market good or the economic value supplied by the good, rather than the demand function itself [23].

As mentioned earlier, the economic value of a particular good or service is assessed in the lower part of the demand function. The demand function is usually estimated using the price and quantity determined through the transaction in the market for the good or service. However, since the non-market good, the management and protection of an endangered marine species, is not traded in 
the market, its price and quantity cannot be observed. In particular, it is illegal to trade FP, which is legally protected in South Korea, in the market. Thus, in order to assess the economic value of the project of managing and protecting the FP, it is necessary to apply the economic technique of creating a hypothetical market, immersing the potential consumer who can enjoy the economic value in the hypothetical market, and making the potential consumer trade the project in the hypothetical market.

The application of the economic technique has a disadvantage in that it requires a costly survey to collect data, and it is difficult in terms of utilization because it requires somewhat complicated economic theories. On the other hand, the non-economic technique assesses the value of a good indirectly by using the costs required for the replacement, control, or recovery of the good. It includes the replacement cost approach, the control cost approach, and the recovery cost approach, and has an advantage that it is efficient and fairly easy to apply in terms of time and cost. However, it has room for criticism in that it regards costs as benefits and is vulnerable to attack due to weak theoretical grounds [24].

Consequently, economic techniques designed for assessing a non-market good should be applied here. These economic techniques are largely divided into the stated preference (SP) and the revealed preference (RP) approaches $[21-23,25]$. The former uses the data that appear as a result of a person's behavior, while the latter uses the data obtained by asking a person about her or his preference. The RP approach is sometimes considered more reliable than the SP approach in that the first only requires observing people's behavior without having to ask people about their preferences. However, the RP approach is quite restrictive because there are only a limited number of objects to which the RP approach can be applied. It is difficult to employ the RP approach, especially in achieving the objective of this study. On the other hand, the SP approach has no restrictions and can be applied to objects to which the RP cannot be applied [26]. Therefore, this study seeks to adopt the SP approach.

The SP approach is made up of the CV and CE approaches. Both approaches have their own advantages and disadvantages. In particular, in order to apply the latter, the non-market goods to be investigated must consist of a variety of attributes, which must be well defined and meaningful, as they are well recognized by the public, which is the subject of the valuation. The CV approach is employed in this study because several attributes are not properly defined for managing and protecting the FP. The reliability and validity of the approach were well verified in the literature $[27,28]$.

The term "contingent" means leading potential consumers to participate in a hypothetical market by creating the market for a non-market good. "Valuation" implies that the economic value of the good is measured through potential consumers' purchasing the good in the market by stating their WTP for the good in the CV survey. Therefore, CV method can be ideally employed in assessing the economic value of managing and protecting the FP. Particularly, when applying CV, hypothetical bias associated with setting up a hypothetical market can be a problem, but can be overcome by introducing a payment vehicle [29]. In this study, the annual income tax per household was set as a payment vehicle, as will be described later. In addition, the process of collecting data through a survey is essential to the application of the CV method. For this reason, understanding the survey methodology and having familiarity with microeconomic theory are important in applied CV work [22,30].

In particular, a seminal paper of Arrow et al. [31] presents methodological guidance that applied $\mathrm{CV}$ research should follow. For example, recommendations include in-person face-to-face interviews instead of mail, telephone, or online interviews during a survey, a sample size of at least 1000, a description of some substitutable goods for the object under investigation, and the use of WTP rather than willingness to accept as a measure of the economic value. Moreover, Johnston et al. [32] discussed guidelines to follow when applying the SP method, including CV. As will be explained below, this study tried to follow most of these guidelines.

\subsection{Survey Instrument and Method}

The first step in creating a survey questionnaire is to accurately define the goods to be evaluated. This involves identifying the business as usual (BAU) state $\left(Q_{0}\right)$ and the target state $\left(Q_{1}\right)$ and clarifying the various policy measures for moving from the BAU to the target states. In this study, the BAU state 
means the state in which no additional action is taken by the government. The target state refers to the goal for which the government wants to take action to reach, that is, the goal to ultimately evaluate. Thus, the goods under evaluation indicate the difference between $Q_{1}$ and $Q_{0}$ rather than the target state $\left(Q_{1}\right)$ itself. In other words, the difference between doing something and doing nothing is assessed in an applied CV study.

In this study, the BAU state is that the South Korean government takes no additional action to protect FPs. The target state is to implement some policies for protecting FPs. The policy measures for moving from the BAU state to the target state are as follows:

- To fulfill the target state, the KMOF monitors population of FP and applies penalties against violation of trying to capture or trade FPs.

- Financial investment for research and development of a new fishing net to prevent FPs from be unintentionally caught.

- Protecting habitats of the FP and providing other activities to increase recognition of the importance of the FP, including an education program.

There were three main parts in the questionnaire. The first part slowly led interviewees to the hypothetical market, asking about their general perception of and experience associated with the goods being evaluated. The first part presents the background and objective of the survey, as shown in Figure A1. The second part described the current state, the target state, and the policy measures for moving from $Q_{0}$ to $Q_{1}$, and then asked the interviewees about their WTP. Before asking the WTP question, the effects expected from protecting the FP were clearly explained to the interviewees to help them make well-informed decisions. The last part asked interviewees about their socioeconomic characteristics, such as their education level, income level, age, and gender. The main part of the survey questionnaire in this study is given in Appendix A.

Initial versions of the survey instrument drawn up by $\mathrm{CV}$ researchers should be refined through small focus group interviews. In this regard, a survey of a 30 member focus group was able to find parts that were unclear and/or difficult to figure out, and to refine the survey instrument more precisely. In addition, basic information for designing the bid amounts to be presented to the respondents could be collected through the focus group interviews. The focus group was formed by a professional survey company.

A random sampling method was commissioned by an expert who was affiliated with a professional polling firm; the sampling reflected the population characteristics observed from a census by Statistics Korea, the Korean National Statistical Office. More specifically, stratified random sampling was conducted. The survey firm performed a random sampling and field CV survey based on a structured questionnaire during August 2018. According to Statistics Korea, there were 19,871,152 households in Korea in 2018. In order to draw a random sample of this population, stratified random sampling was conducted by the polling firm.

Field surveys are typically accomplished through postal questionnaires, telephone interviews, person-to-person interviews, or online surveys. While postal surveys have the advantage of low cost, the typical response rate is relatively low in South Korea, and the sample may reflect sample selection bias. For telephone interviews, the cost is reasonable, and random dialing methods, including calls to mobile phones, allow random sampling. However, it is difficult to present enough information to the interviewees to create a hypothetical market. More and more affordable surveys are being conducted online these days as Internet penetration increases, but there is a high possibility of obtaining a selected sample rather than a random one. Person-to-person interviews have the disadvantage of high cost, but the advantage of being able to ensure a random sample, and they present in full the information needed to immerse the interviewees in the hypothetical market. Furthermore, the interviewees can give answers conveniently through skilled professional interviewers. Therefore, this study employed person-to-person interviews. In addition, in conducting person-to-person interviews, interview experts belonging to professional survey companies visited the respondents' homes instead of selecting respondents in crowded places, such as shopping malls. 


\subsection{How to Elicit WTP Responses}

Usually, eliciting WTP in CV studies can be accomplished through either open- or closed-ended question formats. If the open-ended question format is used, interviewees are directly requested to report their WTP responses in a continuous value. However, interviewees can feel uncomfortable when open-ended questions are asked, which may increase their objection to the survey itself or the probability of reporting protest responses. If the closed-ended question format is adopted, interviewees are asked about whether they have an intention of paying a presented bid or not. This then avoids the problem of protest responses.

On the other hand, using the open-ended question format can obtain continuous-point WTP data, while the closed-ended question format produces only interval data, discrete response data of "yes" or "no." In terms of statistical efficiency, continuous data are superior to interval data, but in terms of data reliability, the closed-ended question is known to be superior to the open-ended question [28]. Therefore, closed-ended questions were applied in this study. This enabled us to avoid interviewees' strategic behavior, which means that they may overstate or understate their WTP [25].

In particular, among several closed-ended questions, the one-and-one-half-bounded (1.5B) question proposed by Copper et al. [33] was used in this study because of its ability to ensure reasonable levels of both consistency and efficiency. For the application of the 1.5B question format, sets of two bid amounts must be established in advance: A lower bid amount $\left(R^{L}\right)$ and a higher bid amount $\left(R^{H}\right)$. Approximately $50 \%$ of the interviewees are first supplied with the lower bid $\left(R^{L}\right)$ and then asked about whether they have an intention of paying $R^{L}$ or not. If the answer is "yes," a follow-up question is posed of whether or not they accept the payment of $R^{H}$, and, otherwise, there are no further questions. The rest of the interviewees are first provided with the higher bid $\left(R^{H}\right)$ and then asked about whether they have an intention of paying $R^{H}$ or not. If the response is "no," they are asked whether they accept the payment of $R^{L}$, and, otherwise, there are no further questions.

Let $M$ be the number of interviewees and $R_{m}$ be a bid offered to interviewee $m$ for $m=1, \ldots, M$. When the bid $\left(R_{m}\right)$ is presented, if the response is "yes," WTP $P_{m}>R_{m}$, and, if the response is "no," $W T P_{m} \leq R_{m}$. Six binary variables concerning the answers reported by the interviewees can be introduced as:

$$
\left\{\begin{array}{l}
D_{m}^{N}=F\left(W T P_{m} \leq R_{m}^{L}\right)=F(m \text { th interviewee responds "no" }) \\
D_{m}^{Y N}=F\left(R_{m}^{L} \leq W T P_{m} \leq R_{m}^{H}\right)=F(m \text { th interviewee responds "yes-no" }) \\
D_{m}^{Y Y}=F\left(R_{m}^{H} \leq W T P_{m}\right)=F(m \text { th interviewee responds "yes-yes" }) \\
D_{m}^{N N}=F\left(W T P_{m} \leq R_{m}^{L}\right)=F(m \text { th interviewee responds "no-no" }) \\
D_{m}^{N Y}=F\left(R_{m}^{L} \leq W T P_{m} \leq R_{m}^{H}\right)=F(m \text { th interviewee responds "no-yes" }) \\
D_{m}^{Y}=F\left(R_{m}^{H} \leq W T P_{m}\right)=F(m \text { th interviewee responds "yes" })
\end{array}\right.
$$

where $F(\cdot)$ becomes 1 when the argument is true and 0 when the argument is not true.

\subsection{Econometric Model for Analyzing the WTP Responses}

The spike model is quite useful when dealing with closed-ended CV data with many zero values [34,35]. The spike model, which is an econometric model for analyzing WTP responses with zero observations, was employed in this research and described below. To identify interviewees with $\mathrm{WTP}=0$, the interviewers further asked those who responded "no" to the bid amount $R_{m}^{L}$ whether their WTP is greater than zero or zero. One more binary variable indicating possible outcomes from the further question is:

$$
D_{m}^{T Y}=F(m \text { th interviewee responds "greater than zero" to the further question) }
$$


Let $G_{W T P}(\cdot)$ be the cumulative distribution of WTP. Employing the logistic function commonly used in the literature, the following form can be derived for $G_{W T P}(\cdot)$.

$$
G_{W T P}\left(R ; \pi_{0}, \pi_{1}\right)=\left\{\begin{array}{c}
{\left[1+\exp \left(\pi_{0}-\pi_{1} R\right)\right]^{-1} \text { if } R>0} \\
{\left[1+\exp \left(\pi_{0}\right)\right]^{-1} \text { if } R=0} \\
0 \text { if } R<0
\end{array}\right.
$$

where $\pi_{0}$ and $\pi_{1}$ are parameters to be estimated.

In particular, the probability that WTP is zero is called the spike. Therefore, the spike is calculated as $\left[1+\exp \left(\pi_{0}\right)\right]^{-1}$. The formula computing the mean WTP is obtained as $\left(1 / \pi_{1}\right) \ln \left[1+\exp \left(\pi_{0}\right)\right]$ from combining the general equation that obtains the mean using the cumulative distribution function and Equation (3). That is, the spike model was estimated using all sample data, including observations with zero WTP, not only using observations with positive WTP. In this regard, when values for a sample are extended to the population, the mean WTP estimate obtained for the sample can be extended over the population. One can generate an estimate of the total WTP for the entire population of the study area by multiplying the estimate per household by the number of households of the area. The spike model takes the following form of a log-likelihood function.

$$
\begin{aligned}
\ln L=\sum_{m=1}^{M}\left\{\left(D_{m}^{Y Y}\right.\right. & \left.+D_{m}^{Y}\right) \ln \left[1-G_{W T P}\left(R_{m}^{H} ; \pi_{0}, \pi_{1}\right)\right]+\left(D_{m}^{Y N}+D_{m}^{N Y}\right) \ln \left[G_{W T P}\left(R_{m}^{H} ; \pi_{0}, \pi_{1}\right)\right. \\
& \left.-G_{W T P}\left(R_{m}^{L} ; \pi_{0}, \pi_{1}\right)\right] \\
& +D_{m}^{T Y}\left(D_{m}^{N}+D_{m}^{N N}\right) \ln \left[G_{W T P}\left(R_{m}^{L} ; \pi_{0}, \pi_{1}\right)-G_{W T P}\left(0 ; \pi_{0}, \pi_{1}\right)\right] \\
& \left.+\left(1-D_{m}^{T Y}\right)\left(D_{m}^{N}+D_{m}^{N N}\right) \ln G_{W T P}\left(0 ; \pi_{0}, \pi_{1}\right)\right\}
\end{aligned}
$$

One can obtain the maximum likelihood estimates for $\pi_{0}$ and $\pi_{1}$ by maximizing Equation (4) with respect to $\pi_{0}$ and $\pi_{1}$. The variables representing interviewees' characteristics are called covariates. We can examine the impact that covariates make on the probability of their saying "yes" to the presented bid with the model containing covariates. Replacing $\pi_{0}$ with $\pi_{0}+y_{r}^{\prime} \omega$ in Equations (3) and (4) gives us the model with covariates, where $y_{r}$ and $\omega$ indicate covariates and their coefficients.

There may be a lot of factors that can affect the interviewee's probability of their saying "yes" to the presented bid. This study gathered data on the following six variables: Education, Income, Head, Gender, Age, and Knowledge. The variables concern socioeconomic characteristics and interviewees' perceptions. Table 2 shows basic information about the variables. The first five variables concern socioeconomic characteristics. The South Korean government is wondering how these respondent characteristics affect their WTP for the management and protection. The variable of Knowledge is concerned with respondents' perceptions. A person with prior knowledge of the FP can recognize the FP more familiarly and appreciate its importance. Thus, interviewees' prior knowledge of the FP can affect their WTP for the management and protection.

Table 2. Basic information about the covariates used.

\begin{tabular}{clcc}
\hline Variables & \multicolumn{1}{c}{ Definitions } & Mean & Standard Deviation \\
\hline Education & The interviewee's education level in years & 14.04 & 2.27 \\
\hline Income & $\begin{array}{l}\text { The interviewee's household's monthly income (Unit: } \\
\text { Million KRW = 849 USD) }\end{array}$ & 4.80 & 5.99 \\
\hline Head & Dummy for the interviewee's being a head of the household & 0.55 & 0.50 \\
\hline Gender & The interviewee's gender (0 = male; $1=$ female) & 0.50 & 0.50 \\
\hline Age & The interviewee's age & 46.55 & 9.48 \\
\hline Knowledge & $\begin{array}{l}\text { Dummy for the interviewee's knowing about the finless } \\
\text { porpoise before the survey }(0=\text { no; } 1 \text { = yes })\end{array}$ & 0.24 & 0.43 \\
\hline
\end{tabular}




\section{Results}

\subsection{Data}

As described earlier, it is necessary to take utmost care in collecting data through a CV survey. In this regard, four important considerations were taken into account in this study. First, the sample size was set at 1000. This is because Arrow et al. [31] proposed 1000 as the number of observations needed for policy decision-making, and the Korea Development Institute, a government-run think tank, also provided a guideline of 1000 for the size of a nationwide sample needed for policy decision-making.

Second, by sampling based on the census data gathered in 2015 by Statistics Korea [36], we tried to make the sample representative of the population. In South Korea, the population census is conducted on a five-year basis, and the 2015 census data were the latest data at the time of the survey. Consequently, we compared the characteristics of the population with those of the sample. Three variables were found for that comparison. The percentages of female respondents in the sample and women in the population were $50.0 \%$ and $49.9 \%$ [36]. The proportions of respondents who lived in Seoul, Gyeonggi, and Pusan Provinces for the sample were 20.1\%, 23.9\%, and 7.2\%, respectively. The equivalent residential proportions for the population were $19.4 \%, 23.7 \%$, and $7.0 \%$. The averages of household income for the sample and for the overall South Korean population were 4.91 million and 4.83 million KRW, respectively. Therefore, it seems that there is no significant gap between the values for the sample and those for the population. The sample characteristics are shown in Figure 1.

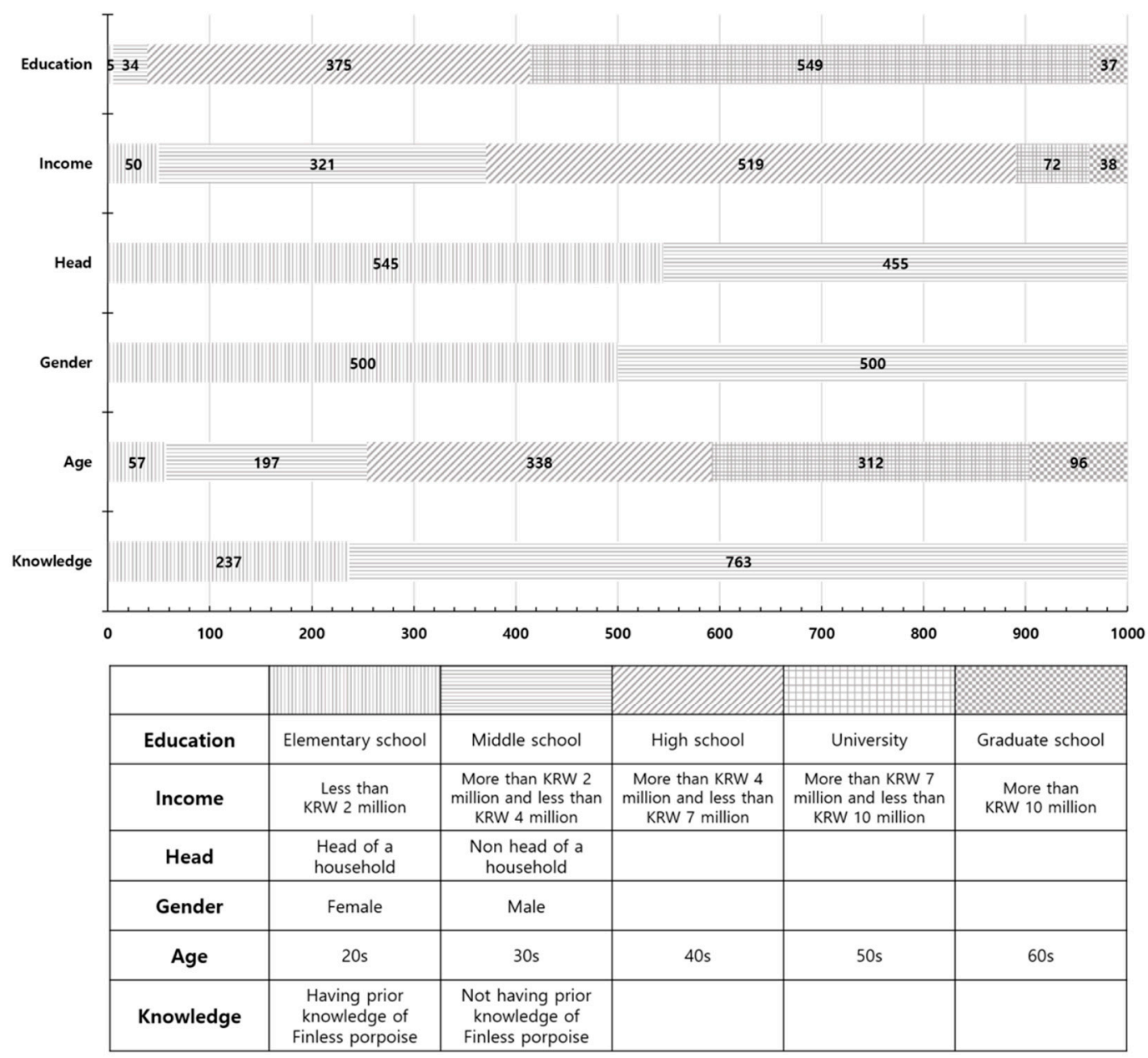

Figure 1. Sample characteristics. 
Third, despite the resultant high cost, a professional polling firm was commissioned to conduct the survey to ensure fairness in sampling and for expertise in implementing face-to-face surveys. Fourth, we chose household income tax as a payment vehicle to help interviewees reveal their actual WTP without difficulty. An appropriate payment vehicle can avoid any bias caused by posing a hypothetical question. This is because, in a hypothetical market situation, interviewees may take the experiment less seriously than in a real situation. In addition, the payment period presented in the CV survey was 10 years.

In summary, a professional survey company in August 2018 conducted a survey of 1000 Korean households with interviewees aged 20-65 years. There were 4539 household visits and attempts to contact to obtain the 1000 final sample data. In other words, the response rate of the CV survey was about $22 \%$. Judging from the comments of the supervisor and interviewers, the survey was implemented without difficulty and was successful enough to collect opinions representative of the population.

Unfortunately, the questionnaire used in this study was not designed to test for an interviewer effect or bias with which the interviewer may influence the CV survey results. However, in this study, two efforts were made to prevent the interviewer effect or bias. First, the authors did not conduct the survey arbitrarily and commissioned a specialized polling agency with extensive CV survey experience. Second, only those who had extensive experience in CV surveys were selected among a number of interviewers belonging to the polling agency and put them into the field CV survey. Therefore, the authors think that the data obtained from the CV survey do not suffer from any interviewer bias.

The distribution of interviewees' answers to the suggested bid is given in Table 3. Each bid that is shown in the first column of Table 3 was offered to a similar number of interviewees. As explained earlier, a "no" answer with regard to paying the lower bid $\left(R_{m}^{L}\right)$ was followed by a further question to confirm whether the interviewee's WTP ranged from zero to the bid or zero. Of the 1000 interviewees, 612 persons indicated a WTP of zero; they have no intention of paying a single cent for managing and protecting FPs.

Table 3. Distribution of willingness to pay answers.

\begin{tabular}{|c|c|c|c|c|c|c|c|c|c|c|}
\hline & & \multicolumn{4}{|c|}{ Lower Bid is Given First (\%) ${ }^{b}$} & \multicolumn{4}{|c|}{ Higher Bid is Given First (\%) ${ }^{b}$} & \multirow[b]{2}{*}{ Sample Size } \\
\hline \multicolumn{2}{|c|}{ Bid Amount ${ }^{a}$} & $R^{H} \leq W T P$ & $R^{L} \leq W T P \leq R^{H}$ & $0 \leq W T P \leq R^{L}$ & $W T P=0$ & $R^{H} \leq W T P$ & $R^{L} \leq W T P \leq R^{H}$ & $0 \leq W T P \leq R^{L}$ & $W T P=0$ & \\
\hline 1000 & 3000 & $101(7.7)$ & $18(12.6)$ & $2(1.4)$ & $41(28.7)$ & $18(12.6)$ & $10(7.0)$ & $3(2.1)$ & $\begin{array}{c}40 \\
(28.0)\end{array}$ & $143(100.0)$ \\
\hline 2000 & 4000 & $14(9.8)$ & $12(8.4)$ & $5(3.5)$ & $40(28.0)$ & $20(14.0)$ & $8(5.6)$ & $5(3.5)$ & $\begin{array}{c}39 \\
(27.3)\end{array}$ & $143(100.0)$ \\
\hline 3000 & 6000 & $5(3.5)$ & $10(7.0)$ & $9(6.3)$ & $47(32.9)$ & $11(7.7)$ & $8(5.6)$ & $8(5.6)$ & $\begin{array}{c}45 \\
(31.5)\end{array}$ & $143(100.0)$ \\
\hline 4000 & 8000 & $2(1.4)$ & $11(7.7)$ & $11(7.7)$ & $48(33.6)$ & $8(5.6)$ & $5(3.5)$ & $9(6.3)$ & $\begin{array}{c}49 \\
(34.3)\end{array}$ & $143(100.0)$ \\
\hline 6000 & 10,000 & $7(4.9)$ & $11(7.7)$ & $14(9.9)$ & $39(27.5)$ & $11(7.7)$ & $2(1.4)$ & $9(6.3)$ & $\begin{array}{c}49 \\
(34.5)\end{array}$ & $142(100.0)$ \\
\hline 8000 & 12,000 & $4(2.8)$ & $8(5.6)$ & $21(14.8)$ & $38(26.8)$ & $10(7.0)$ & $0(0)$ & $12(8.5)$ & $\begin{array}{c}49 \\
(34.5)\end{array}$ & $142(100.0)$ \\
\hline 10,000 & 15,000 & $3(2.1)$ & $6(4.2)$ & $17(11.8)$ & 46 (31.9) & $10(7.0)$ & $2(1.4)$ & $18(12.5)$ & $\begin{array}{c}42 \\
(29.2)\end{array}$ & $144(100.0)$ \\
\hline \multicolumn{2}{|c|}{ Totals } & $46(4.6)$ & $76(7.6)$ & $79(7.9)$ & $299(29.9)$ & $88(8.8)$ & $35(3.5)$ & $64(6.4)$ & $\begin{array}{c}313 \\
(31.3)\end{array}$ & $1000(100.0)$ \\
\hline
\end{tabular}

Notes: ${ }^{a}$ The unit is Korean won, and when the survey was performed, 1.0 USD equaled $1178 \mathrm{KRW} .{ }^{\mathrm{b}}$ The percentage of the answers is reported in parentheses beside the number of answers.

\subsection{Estimation Results}

The findings from estimating the model are presented in Table 4. By performing maximum likelihood estimation, we could obtain the parameter estimates for the model. Concerning the model specification test, the Wald statistic can be computed. The hypothesis to be tested is that the model is insignificant or meaningless. The statistic and its $p$-value are 214.16 and 0.000 , respectively, which implies that we can reject the hypothesis. Consequently, the model has statistical significance. Interestingly, the estimate for the spike (0.6145) is close to the sample ratio of "no-no" and "no-no-no" answers $(61.2 \%)$, which corroborated the usefulness of the spike model. 
The estimate for mean household WTP was derived as 2730 KRW (2.32 USD) per year through the following calculation process: Mean WTP $=\frac{1}{b} \ln (1+\exp (a))=\frac{1}{0.1786} \ln (1+\exp (-0.4645)) \times 1000=$ 2730. Note that we set the unit of the bid amount as $1000 \mathrm{KRW}$ for convenience. The confidence intervals of the estimate for $95 \%$ and $99 \%$ levels can be calculated from the procedure shown in Krinsky and Robb's [37] paper. More specifically, 5000 replications of resampling the parameters from bi-variate normal distribution constructed with the estimation results of $\pi_{0}$ and $\pi_{1}$ produced these confidence intervals. Although this method has limitations that assume that the two parameters follow bi-variate normal distribution, it has the advantage of making it relatively easy for researchers to obtain confidence intervals. In addition, the performance is known to be better than simple methods of calculating confidence intervals using standard errors [37]. Table 2 also contains the computed confidence intervals.

Table 4. Estimation results of the model.

\begin{tabular}{|c|c|}
\hline Variables & Coefficient Estimates \\
\hline Constant & $-0.4645(-7.20) \#$ \\
\hline Bid amount ${ }^{a}$ & $-0.1786(-17.12) \#$ \\
\hline Spike & $0.6145(40.21)^{\#}$ \\
\hline Mean willingness to pay per household per year & $2730 \mathrm{KRW}$ (2.32 USD) \\
\hline$t$-value & $14.63^{\#}$ \\
\hline $95 \%$ confidence interval ${ }^{b}$ & 2403 to 3126 KRW (2.03 to 2.65 USD) \\
\hline $99 \%$ confidence interval $b$ & 2308 to 3279 KRW (1.96 to 2.80 USD) \\
\hline Number of observations & 1000 \\
\hline Log-likelihood & -1077.48 \\
\hline Wald statistic ( $p$-value $)^{c}$ & $214.16(0.000)$ \\
\hline
\end{tabular}

Notes: ${ }^{\mathrm{a}}$ The unit is 1000 Korean won, and 1.0 USD equaled $1178 \mathrm{KRW}$ at the time of the survey. ${ }^{\mathrm{b}}$ The confidence intervals are calculated by the use of Krinsky and Robb's [37] method. ${ }^{c}$ The null hypothesis is that all the parameters are jointly $0 .{ }^{\#}$ denotes statistical significance at the $1 \%$ level.

\subsection{Discussion of the Results}

Since the whole sample may not be identical at the national level, segmenting and then analyzing the sample according to the sample characteristics provides us with some interesting findings. However, the sample size adopted in this study is only 1000, and the segmentation may decrease the number of observations to be analyzed, thereby reducing the statistical efficiency. In such cases, it may be more useful to reflect sample characteristics as covariates in the model rather than to segment the sample.

The spike model has no other covariates except for constant term and bid amount. However, there can be other factors influencing the likelihood of stating "yes" to an offered bid; for example, the age, gender, and education level of the interviewee. The interviewee's household income is also one of the commonly used covariates. Thus, a model containing covariates can be introduced for investigating the impact that covariates make on the likelihood. Concerning the covariates, six variables that are related to the interviewees' characteristics were selected. The basic information about the covariates used was shown in Table 2. Table 5 describes the estimation results of the model with covariates.

All of the estimated values show statistical significance. The positive sign of the estimated coefficient indicates that the greater the covariate, the greater the possibility of responding "yes" to an offered bid. The figures for all variables except Age are positive. The education level of the interviewee has a positive correlation with the probability of stating "yes" to a presented bid. Households with more income have a higher possibility, compared to those with less income, to report "yes" to a provided bid. Interviewees who are heads of their households are more likely to answer "yes" to a suggested bid compared to those who are not. Female interviewees are more likely to give a "yes" answer to a supplied bid than male ones. Interviewees who knew the FP before the survey are more likely to answer "yes" to a suggested bid compared to those who did not. However, the coefficient for 
the Age variable has a negative sign. This indicates that older interviewees are less likely to answer "yes" than younger ones to a given bid.

Table 5. Estimation results of the model with covariates.

\begin{tabular}{|c|c|}
\hline Variables $^{a}$ & Coefficient Estimates ( $t$-Values) \\
\hline Constant & $-1.8023(-2.31)^{\#}$ \\
\hline Bid amount ${ }^{b}$ & $-0.1899(-17.25) \#$ \\
\hline Education & $0.0930(2.84)^{\#}$ \\
\hline Log of Income & $0.2900(1.84) \#$ \\
\hline Head & $0.6481(2.29){ }^{\#}$ \\
\hline Gender & $0.8289(2.89){ }^{\#}$ \\
\hline Knowledge & $0.9317(6.40)^{\#}$ \\
\hline Age & $-0.0216(-2.85) \#$ \\
\hline Spike & $0.6195(39.35)$ \\
\hline Mean household willingness to pay per year & 2522 KRW (2.14 USD) \\
\hline$t$-value & $14.56^{\#}$ \\
\hline $95 \%$ confidence interval $^{\mathrm{c}}$ & 2212 to $2902 \mathrm{KRW}$ (1.88 to $2.46 \mathrm{USD}$ ) \\
\hline $99 \%$ confidence interval ${ }^{c}$ & 2111 to $3015 \mathrm{KRW}$ (1.79 to $2.56 \mathrm{USD}$ ) \\
\hline Wald statistic ( $p$-value $)^{\mathrm{d}}$ & $212.09(0.000)$ \\
\hline Log-likelihood & -1040.43 \\
\hline Number of observations & 1.000 \\
\hline
\end{tabular}

Notes: ${ }^{\mathrm{a}}$ The variables are explained in Table $2 .{ }^{\mathrm{b}}$ The unit is Korean won, and 1.0 USD equaled $1178 \mathrm{KRW}$ at the time of the survey. ${ }^{c}$ The confidence intervals are calculated by the use of Krinsky and Robb's [37] method. ${ }^{d}$ The null hypothesis is that all the parameters are jointly $0 .{ }^{\#}$ denotes statistical significance at the $10 \%$ level.

After obtaining the yearly mean WTP for each household, the next step is to estimate aggregate values. We need to adjust the sample value to the population value, retaining representativeness. The authors believe that this sample is representative and well balanced in two aspects, as discussed above. First, the survey represented the recommended statistical power of 1000 people and was conducted by skilled, professional interviewers. Second, there were no significant differences between the characteristics of the sample and the overall population. In addition, the spike model was estimated using all sample data, including observations with zero WTP, not only using observations with positive WTP. In this regard, when values for a sample are extended to the population, the mean WTP estimate obtained for the sample can be extended over the population.

The mean WTP in Table 4 was used for the adjustment to prevent covariates from affecting the mean WTP estimate. The mean household WTP estimate multiplied by the total number of households in South Korea is the total WTP adjusted for the population. There were 19,871,152 households in the country when the survey was underway [36]. The mean household WTP was estimated to be $2730 \mathrm{KRW}$ (2.32 USD). The population's total WTP for managing and protecting the FP is 54.19 billion KRW (46.00 million USD) per year. The management and protection significantly contribute to South Korean households' utility.

This value implies the economic benefits of managing and protecting the FP. If the economic benefits exceed the costs involved in the management and protection, the management and protection re socially profitable and should be immediately and continuously carried out. It seems socially beneficial given that the magnitude of the benefits is not small, although strictly estimating the costs is not attempted here, as it is a difficult task and goes beyond the scope of this study. In addition, the research structure taken and major results obtained in this study could be a reference in the formulation and determination of a policy for other endangered marine species not only in South Korea, but also in other countries.

As described earlier, $76.3 \%$ of all respondents were not aware of the FP in advance, and $61.2 \%$ of all respondents indicated zero WTP. Nevertheless, the estimated mean WTP was statistically significant. This implies the possibility of increasing WTP by raising public awareness of the FP. Therefore, in order 
for the management and protection of the FP to be supported by the people, it is necessary to discover and implement policy instruments to publicize the FP to the public, such as awareness campaigns.

In terms of the object to be valued, Dong's [13] study is the most similar to this study. However, it is difficult to directly compare the findings from the two studies because this study differs from Dong's [13] study in five respects: Sample size, survey method, the time of the survey, the model, and estimated mean WTP. First, this study utilized 1000 observations, whereas Dong [13] utilized only 240 observations. Second, this study conducted in-person face-to-face interviews, but Dong [13] conducted a market stall survey. Third, our survey was implemented during August 2018, but Dong's [13] survey was implemented during October and November 2009. Fourth, regarding the WTP model, this study applied the spike model, but Dong [13] applied the multiple linear regression model. Fifth, the mean WTP was estimated to be 2730 KRW (2.32 USD) per household per year in this study, but Dong [13] reported the mean WTP as 9.94, 5.92, and 6.67 EUR (13.92, 8.29, and 9.34 USD) per household per year in three Chinese cities (Beijing, Guangzhou, and Nanchang), respectively. In addition, although both Dong [13] and this study selected the FP as the object to be valued, in this study, protection of the FP by various means was evaluated, whereas in Dong's [13] study, preservation of the FP's habitat to protect the FP was valued. The WTP estimates obtained from both studies can be expressed as a constant price in 2010 using the real exchange rate of USD. When the real effective exchange rate for 2010 was 100, the real effective exchange rates of USD in 2009 and 2018 were 104.699 and 112.986, respectively [38]. Using these values, the yearly household WTP estimates for three Chinese cities (Beijing, Guangzhou, and Nanchang) given in Dong's [13] book were 13.30, 7.92, and 8.92 in international constant dollars, respectively. The yearly household WTP estimate for South Korea was 2.05 in international constant dollars.

\section{Conclusions}

The South Korean government planned to manage and protect FPs living in the country's West Sea and desperately needed information about the public WTP for the management and protection. Therefore, we examined what value the public puts on the management and protection using data collected from a nationwide CV survey of 1000 households. The yearly mean household WTP for the management and protection was estimated, with statistical significance, to be $2730 \mathrm{KRW}$ (2.32 USD). This value implies the economic value or benefits arising from the management and protection. In conclusion, the public revealed a significant WTP for the management and protection, and this was socially beneficial.

The economic value ensuing from the management and protection is largely divided into use value and non-use value [21]. The non-use value can then be subdivided into existence value, bequest value, and option value. In general, it is not possible to divide the economic value obtained from a CV study into use value and non-use value. Therefore, the value found from this study needs to be interpreted as a total economic value that includes both use value and non-use value. It is not appropriate to add the value obtained by using a different methodology to the value obtained from this study.

The economic value estimate for the FP presented in this study is important information for policy makers and researchers. First, it can be used as basic data in cost-benefit analysis to assess the validity of the costs required to implement the policies for FP protection. Second, it can be utilized to determine policy priorities. In South Korea, 80 species of marine life are currently designated and managed as endangered marine species. Since policies for the protection of endangered marine species are implemented under a limited budget and manpower, it is necessary to determine priorities and distribute budgets for endangered marine species. Economic value information for each endangered marine species can be useful for these decisions. Third, the economic value of the FP may be used as a basis for estimating the economic damage amount in the event of an accident in which the habitat of the FP is damaged, such as an oil spill or hazardous substance leak. 
The findings from this study have policy as well as research implications. This study provided the basis for decision-making about whether to continue the management and protection or not by estimating the economic value or benefits arising from management and protection. As taxes collected from the public will be used for the management and protection, it is important for policy-makers to confirm whether the public supports the management and protection. Furthermore, we believe that this research added evidence to the literature and provided a useful reference for future researchers by investigating the public perspective on managing and protecting the FP.

Author Contributions: All three authors played their own significant roles in planning and writing this paper. J.-H.K. proposed ideas for the paper, laid out the basic framework for the survey, and wrote half of the paper; J.K. completed a final version of the questionnaire and analyzed the model using the collected data; and S.-H.Y. supervised the entire course of the research, wrote part of the paper, and refined the entire paper. All authors have read and agreed to the published version of the manuscript.

Funding: This research is part of the project entitled "Marine ecosystem-based analysis and decision-making support system development for marine spatial planning," funded by the Korean Ministry of Oceans and Fisheries (grant number 20170325).

Conflicts of Interest: The authors declare no conflict of interest.

\section{Appendix A. Main Part of the Survey Questionnaire}

\section{Appendix A.1. Part 1. Questions about Socio-Economic Characteristics}

The interviewees were asked to respond about their socio-economic characteristic, such as the gender of the individual, the number of family members, the level of education, and the monthly income per household (before tax deduction). Questions about the number of family members and income were open-ended questions, and the question about the level of education was as follows:

Q1. Please check with $\sqrt{ }$ your education level in years.

\begin{tabular}{ccccccc}
\hline Education Level & Uneducated & Elementary School & Middle School & High School & University & Graduate School \\
\hline $\begin{array}{c}\text { Education level } \\
\text { in years }\end{array}$ & 0 & 123456 & 789 & 101112 & 13141516 & 17181920 \\
\hline
\end{tabular}

Appendix A.2. Part 2. Questions about Willingness to Pay for Protecting the Finless Porpoise (FP) in South Korea

Type A. Q1. Is your household willing to pay additional income tax of 1000 Korean won (lower bid amount) annually for the next ten years for protecting the FP in South Korea, supposing that the protection is certain to succeed?

a. Yes-go to Type A. Q2.

b. No-go to Q3.

Type A. Q2. Is your household willing to pay additional income tax of about 3000 Korean won (upper bid amount) annually for the next ten years for protecting the FP in South Korea, supposing that the protection is certain to succeed?

a. Yes-Finish this survey

b. No-Finish this survey

Type B. Q1. Is your household willing to pay additional income tax of about 3000 Korean won (upper bid amount) annually for the next ten years for protecting the FP in South Korea, supposing that the protection is certain to succeed?

a. Yes-Finish this survey

b. No-go to Type B. Q2.

Type B. Q2. Is your household willing to pay additional income tax of about 1000 Korean won (lower bid amount) annually for the next ten years for protecting the FP in South Korea, supposing that the protection is certain to succeed? 
a. Yes-Finish this survey

b. No-go to Q3.

Q3. Then, is your household not willing to pay anything for protecting the FP in South Korea?

a. Yes, our household is willing to pay something less than 1000 Korean won.

b. No, our household is not willing to pay anything. In other words, our household's willingness to pay is zero.

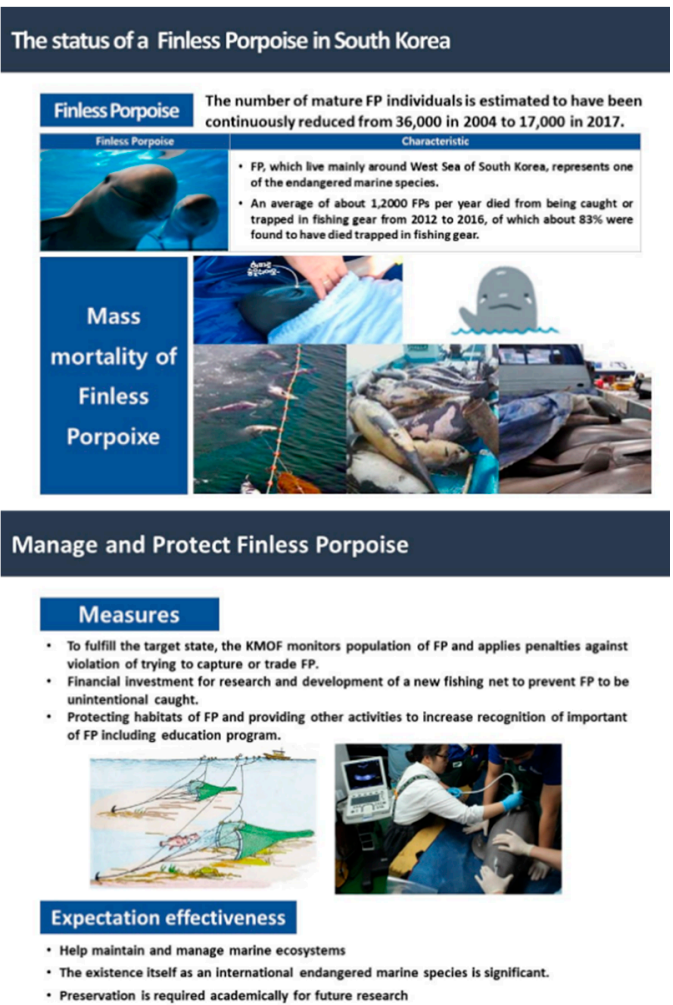

Figure A1. Information materials used to inform interviewees about the finless porpoise.

\section{References}

1. International Union for Conservation of Nature. Red List of Threatened Species. 2019. Available online: https://www.iucn.org/resources/conserbvation-tools/iucn-red-list-threatened-species (accessed on 20 March 2020).

2. Korea Ministry of Oceans and Fisheries. Press Release for Conservation and Management of Marine Ecosystems Act. 2006. Available online: http://www.mof.go.kr (accessed on 20 March 2020).

3. Korean Ministry of Oceans and Fisheries. Press Release for Renewed List of Protection for Endangered Marine Species Including Finless Porpoise. 2016. Available online: http://www.mof.go.kr (accessed on 20 March 2020).

4. International Union for Conservation of Nature. New Red List Assessments for Two Species of Finless Porpoises. 2019. Available online: https://www.iucn.org/new-red-list-assessments-for-two-species-offinless-porpoises (accessed on 20 March 2020).

5. Gao, A.; Zhou, K. Growth and reproduction of three populations of finless porpoise, Neophocaena phocaenoides, in Chinese waters. Aquat. Mamm. 1993, 19, 3-12.

6. Kim, H.J.; Jin, S.J.; Yoo, S.H. Public assessment of releasing a captive indo-pacific bottlenose dolphin into the wild in South Korea. Sustainability 2018, 10, 3199. [CrossRef]

7. Davies, K.T.; Brillant, S.W. Mass human-caused mortality spurs federal action to protect endangered North Atlantic right whales in Canada. Mar. Policy 2018, 104, 157-162. [CrossRef]

8. Guzman, J. How Can they Count Whales from Space? Available online: https://thehill.com/changing-america (accessed on 10 May 2020). 
9. Sèbe, M.; Christos, A.K.; Pendleton, L. A decision-making framework to reduce the risk of collisions between ships and whales. Mar. Policy 2019, 109, 103697. [CrossRef]

10. Giraud, K.; Turcin, B.; Loomis, J.; Cooper, J. Economic benefit of the protection program for the Steller sea lion. Mar. Policy 2002, 26, 451-458. [CrossRef]

11. Stithou, M.; Scarpa, R. Collective versus voluntary payment in contingent valuation for the conservation of marine biodiversity: An exploratory study from Zakynthos, Greece. Ocean Coast. Manag. 2012, 56, 1-9. [CrossRef]

12. Bosetti, V.; Pearce, D.W. A study of environmental conflict: The economic value of Grey Seals in southwest England. Biodivers. Conserv. 2003, 12, 2361-2392. [CrossRef]

13. Dong, Y. Contingent Valuation of Yangtze Finless Porpoises in Poyang Lake, China; Springer Science \& Business Media: Berlin, Germany, 2012.

14. Lim, S.Y.; Jin, S.J.; Yoo, S.H. The economic benefits of the Dokdo Seals restoration project in Korea: A contingent valuation study. Sustainability 2017, 9, 968. [CrossRef]

15. Boxall, P.C.; Adamowicz, W.L.; Olar, M.; West, G.E.; Cantin, G. Analysis of the economic benefits associated with the recovery of threatened marine mammal species in the Canadian St. Lawrence Estuary. Mar. Policy 2012, 36, 189-197. [CrossRef]

16. Bond, C.A.; Cullen, K.G.; Larson, D.M. Joint estimation of discount rates and willingness to pay for public goods. Ecol. Econ. 2009, 68, 2751-2759. [CrossRef]

17. Lew, D.K.; Layton, D.F.; Rowe, R.D. Valuing enhancements to endangered species protection under alternative baseline futures: The case of the Steller sea lion. Mar. Resour. Econ. 2010, 25, 133-154. [CrossRef]

18. Lew, D.K. Willingness to pay for threatened and endangered marine species: A review of the literature and prospects for policy use. Front. Mar. Sci. 2015, 2, 96. [CrossRef]

19. Habb, T.C.; McConnell, K.E. Valuing Environmental and Natural Resources; Edward Elgar: Cheltenham, UK, 2002.

20. Brent, R.J. Applied Cost-Benefit Analysis, 2nd ed.; Edward Elgar: Cheltenham, UK, 2006.

21. Freeman, A.M., III; Herriges, J.A.; Kling, C.L. The Measurement of Environmental and Resource Values: Theory and Methods, 3rd ed.; RFF Press: New York, NY, USA, 2014.

22. Haab, T.; Lewis, L.; Whitehead, J. State of the Art of Contingent Valuation. In Oxford Research Encyclopedia of Environmental Science; Oxford University Press: Oxford, UK, 2020.

23. Freeman, A.M. The Measurement of Environmental and Resource Values: Theory and Methods; Resources for the Future: Washington, DC, USA, 1993.

24. Hohmeyer, O.; Ottinger Richard, L. External Environmental Costs of Electric Power: Analysis and Internalization; Springer: Berlin, Germany, 1990.

25. Flores, N.E. A Conceptual framework for nonmarket valuation. In A Primer on Nonmarket Valuation, 2nd ed.; Champ, P.A., Boyle, K.J., Brown, T.C., Eds.; Springer: Dordrecht, The Netherlands, 2017.

26. Bateman, I.J.; Carson, R.T.; Day, B.; Hanemann, M.; Hanley, N.; Hett, T.; Sugden, R. Economic Valuation with Stated Preference Techniques: A manual; Edward Elgar Publishing: Cheltenham, UK, 2002.

27. Garrod, G.; Willis, K.G. Economic Valuation of the Environment; Edward Elgar: Cheltenham, UK, 1999.

28. Mitchell, R.C.; Carson, R.T. Using Surveys to Value Public Goods: The Contingent Valuation Method; Resources for the future: Washington, DC, USA, 1989.

29. Champ, P.A.; Moore, R.; Bishop, R.C. A Comparison of Approaches to Mitigate Hypothetical Bias. Agric. Resour. Econ. Rev. 2009, 38, 166-180. [CrossRef]

30. Carson, R. Contingent Valuation: A Comprehensive Bibliography and History; Edward Elgar: Cheltenham, UK, 2012.

31. Arrow, K.; Solow, R.; Portney, P.R.; Leamer, E.E.; Radner, R.; Schuman, H. Report of the NOAA panel on contingent valuation. Fed. Regist. 1993, 58, 4601-4614.

32. Johnston, R.J.; Boyle, K.J.; Adamowicz, W.; Bennett, J.; Brouwer, R.; Cameron, T.A.; Hanemann, W.M.; Hanley, N.; Ryan, M.; Scarpa, R.; et al. Contemporary guidance for stated preference studies. J. Assoc. Environ. Resour. Econ. 2017, 4, 319-405. [CrossRef]

33. Cooper, J.C.; Hanemann, M.; Signorello, G. One and one-half bound dichotomous choice contingent valuation. Rev. Econ. Stat. 2002, 84, 742-750. [CrossRef]

34. Kriström, B. Spike models in contingent valuation. Am. J. Agric. Econ. 1997, 79, 1013-1023. [CrossRef] 
35. Yoo, S.H.; Kwak, S.J. Using a spike model to deal with zero response data from double bounded dichotomous contingent valuation survey. Appl. Econ. Lett. 2002, 9, 929-932. [CrossRef]

36. Statistics Korea. Korea Statistical Information Service. Available online: http://kosis.kr (accessed on 20 March 2020).

37. Krinsky, I.; Robb, A.L. On approximating the statistical properties of elasticities. Rev. Econ. Stat. 1986, 68, 715-719. [CrossRef]

38. Statistics Korea. Exchange Rates and Prices. Available online: http://kosis.kr (accessed on 20 May 2020).

(C) (1)

(C) 2020 by the authors. Licensee MDPI, Basel, Switzerland. This article is an open access article distributed under the terms and conditions of the Creative Commons Attribution (CC BY) license (http://creativecommons.org/licenses/by/4.0/). 